\title{
The Effect of Mobile Health and Social Inequalities on Human Development and Health Outcomes: mHealth for Health Equity
}

\author{
Sajda Qureshi \\ University of Nebraska Omaha \\ squreshi@unomaha.edu
}

\author{
Jason Xiong \\ Appalachian State University \\ xiongji@appstate.edu
}

\author{
Becky Deitenbeck \\ University of Nebraska Omaha \\ bdeitenbeck@unomaha.edu
}

\begin{abstract}
The equitable provision of healthcare entails the distribution of resources and other processes to overcome health inequality. The concept of heath equity suggests that differences in social and economic backgrounds of people affect their ability to lead the lives they choose to live. Following a review of what is known about health equity, social determinants of health equity and the role of mobile health, this paper investigates the relationship between mHealth, social inequalities in life expectancy and in education on Human Development and Health and Wellbeing. The analysis discovers a significant relationship between mHealth, social inequalities in human development and health outcomes. These findings have important implications for the use of mHealth applications to achieve health equity. The contribution of this paper is in understanding the role of social inequalities in and mHealth in enabling people to bring about improvements in the lives they lead and in their health outcomes.
\end{abstract}

Keywords: Health equity, human development, health, wellbeing, mHealth.

\section{Introduction}

The need for health equity arises from inequalities in health status, health care utilization and health care financing [1]. There is a sense that the equitable provision of healthcare is central to achieving development in any society. The provision of equitable healthcare is important because a nation's prosperity depends on a healthy population. However, due to the vast scattered rural and remote communities throughout much of the World, social determinants, and poor access to primary health care, health disparities persist globally [2,3].

Health inequalities exist within countries, towns and cities. The life expectancy of a girl born today is greater than 80 years old in some countries, but less than 45 in other countries [32]. But this disparity is not just between rich and poor countries. In Boston and Washington D.C., the life expectancy is cut short by 20 years for a person living in the poor part of the city [34]. Similarly, men living in the poorest part of Calton, Glasgow have a life expectancy of 54 years, while men living in India have a life expectancy of 63 years[34]. In order to reduce the disparities, considerable research exists that indicate good primary health care is associated with improved health outcomes, advance equity in heath, and reduced costs [4-6].

Mobile health (mHealth) technology has expanded access to healthcare. A person has more options and accessibility to healthcare beyond the traditional hospital and health care clinics. Mobile healthcare applications are helping people become healthier and may potentially bridge the gap among rural and remote communities. By 2012, at least 40,000 health related apps were available to download to help people research and manage their health [7]. These apps ranged from chronic disease management, ability to access relevant health care information, exercise and food intake tracking, follow-up care and basic diagnostics for minor medical issues [8]. In addition, health care systems as well as county and state officials are using apps to improve public health concerns. For example, mHealth thermometer was used to predict seasonal flu outbreaks sooner in China [9].

Worldwide, over $85 \%$ of the population has mobile-cellular signal coverage [10]. According to the International Communications Union (ICU), in 2017, an estimated 103.5 per 100 inhabitants had a wireless subscription. This is up from 33.5 per 100 inhabitants in 2005. In addition, the growth is even more impressive in the least developed countries (LDCs) from 5.0 in 2005 to 70.4 (estimated) in 2017 [10]. mHealth has the potential to improve global health by bolstering health systems and advance development initiatives within countries [11].

With the ethical dimension, equitable healthcare provision does not necessarily mean that everyone should have the same access to healthcare, but that people should be able to access the care that they 
require and live the lives that they value [1]. Sahay suggests that studies that conceptualize development based on the Human Development Index have helped in the reconceptualization of an alternative social future with multiple influences, including relating to classifications of development and with it flows of development aid [1]. In IS, Walsham's writings have helped to introduce the interpretive research paradigm as a challenge to the positivist orthodoxy, and provide the space for researchers to sketch out multiple and alternative interpretively inspired perspectives." [1 p.169].

This paper investigates the role of social inequalities, education and life expectancy, on human development and heath. We create a model with three indexes we include as independent variables for our model. The first index we create helps us measure mHealth (Mobile Phone Subscriptions, Internet User Health Index), and two indexes that help us measure social inequalities (Inequality-Adjusted Life Expectancy and Mobile Phone Subscriptions Index (LEMPSI) and Inequality-Adjusted Education and Mobile Phone Subscriptions Index (EIMPSI)). The dependent variables in our model are the Human Development Index (HDI) and Health Index (HI). The dependent variables help us understand the extent to which people can live the lives they chose to live (HDI) and be healthy (HI).

The following sections offer a theoretical background of the importance of health equity, social disparities, and mobile health for equitable healthcare provision.

\section{Theoretical Background}

\subsection{Health Equity}

The concept of heath equity arose from the belief that differences in social and economic backgrounds of people lead to differences in their ability to access health care. In other words, groups of people who are already socially disadvantaged due to their poverty, gender, racial, ethnic or religious backgrounds are further disadvantaged with respect to their health [12]. Braveman and Gruskin [13] offer a conceptual definition that they operationalize as follows:

"equity in health is the absence of systematic disparities in health (or in the major social determinants of health) between groups with different levels of underlying social advantage/disadvantagethat is, wealth, power, or prestige.... health is essential to wellbeing and to overcoming other effects of social disadvantage." [13], p.254.
Equity in healthcare represents both physical and mental wellbeing in which key social determinants include household living conditions, conditions in communities and workplaces and access to healthcare [13]. Health indicators, such as health worker density and distribution and births attended by skilled health personnel, and universal health coverage are important when assessing health equity. Countries, such as Vietnam, Mexico, and China have all experienced gains in health equity since the implementation of universal health coverage. In addition, these countries have experienced a decline in infant mortality $[14,15]$. The life expectancy of a person with a high level of education is six years more than a person with a low level of education in the Netherlands. Likewise, a person, in the Netherlands, with a perceived good health has a life expectancy of 19 years longer [35].

When it comes to understanding disparities in access and outcomes, there is a measurement challenge. Braveman [16] in 2006 explains this challenge well:

"Comparing the health of a disadvantaged group with average levels of health may not be very informative about social inequalities in health. For example, in a setting in which a large proportion of a population is disadvantaged, the health of the most disadvantaged may be markedly different from that of the best-off social group but not very different from the average" (p.178)

In order to understand differences between groups, the World Health Organization (WHO) uses infant mortality as a health indicator to measure inequalities. It also measures differences between the richest and poorest in a country. While the WHO measurement methods show the disparities between the healthiest and sickest in a society, it does not take into account the differences between the poorest and richest or between those in historically disenfranchised and in the dominant racial/ethnic groups. In the United States socioeconomic disparities in populations have generally been categorized according to income or educational attainment, comparing all other groups with the highest income/education group and racial/ethnic backgrounds when assessing health disparities [16].

\subsection{Social Determinants of Health Equity}

The social determinants of health (SDOH) are especially important. In the United States, for example, a similar health condition exist between low-income your men and high-income men in their sixties [17]. Health equity affects education outcomes and income rates, people who suffered a chronic illness in childhood are adversely affected compared to their 
peers [18]. It is also known that neighborhood gardens placed in low income neighborhood provide healthy food to those living in that neighborhood. Therefore, it is vital to understand the health disparities in both health and non-health sectors to improve health equity globally.

Social Determinants of Health (SDOH) are, according to the World Health Organization, "are the conditions in which people are born, grow, live, work and age. These circumstances are shaped by the distribution of money, power and resources at global, national and local levels. The social determinants of health are mostly responsible for health inequities - the unfair and avoidable differences in health status seen within and between countries. " [19].

Social environment/living conditions, such as drinking water, clean cities and sanitation are equally important to population health. Several researchers have documented that exposure to things, such as air pollution and proximity to toxic sites, increases the risk of cardiovascular and respiratory mortality [20-22].

In addition, poor living conditions are occurring everywhere. In fact, more people live in cities that ever before and the health inequality is growing [23]. This is important for policy makers from the local to global economy's. Poverty limits access to quality foods and a safe place to live. In addition, communities with poor $\mathrm{SDOH}$ are plagued with low income, unsafe housing and substandard education. Utilizing and applying the data from $\mathrm{SDOH}$, health both locally and globally will be improved as well as progressing health equity [19].

\subsection{Mobile Health (mHealth)}

mHealth is defined as the use of portable electronic devices for mobile voice or data communication over a cellular or other wireless network of base stations to provide health information [24]. An area in which mobile healthcare provision is becoming more equitable is in enabling care to become more patient centered. Studies have shown that the outcomes of patient centered care have reported better recovery from their discomfort and concern, better emotional health, and fewer diagnostic tests and referrals [25, 26]. Additional studies have also shown that the use of mHealth applications for patient centered care reduce the cost of care significantly [27, 28].

Motivated by rising costs of healthcare, patients can achieve significant improvements in their health outcomes at reduced costs when they use mobile applications. Uses of mobile health applications give people more choices as to how they may go about leading heathier lives. The WHO Tobacco Free Initiative is one example where mHealth has been identified as a cost- effective, scalable and sustainable platform [33]. Kahn, et al. [24] argues that mHealth may also have a non-health benefit: fostering local economic development beyond health care.

Internet enabled mobile applications allow active patient participation in decisions affecting their health status, health information, linking people and information through multiple digital devices to allow for person-to-person communication, and participating in support groups [27]. The use of such mobile applications is transforming the relationship between physicians and patients offering greater equity in outcomes. While the successful cases of mHealth offer hope to those in need of basic healthcare, it is not clear if at all they can be sustained, scaled up, or even replicated globally.

\section{Research Model}

Health Equity outcomes are measured in terms of the Human Development Index (HDI) which was created to define how economic growth should be measured in terms of human development or the ability of people to lead the lives they choose to live. The HDI "is a summary measure of average achievement in key dimensions of human development: a long and healthy life, being knowledgeable and have a decent standard of living. The HDI is the geometric mean of normalized indices for each of the three dimensions" [29]. HDI indicates that a development of a country should be based on people and their capabilities [29]. This is important because a healthy population has a lower cost of medical care and more workers available for the workforce [30]. The research model describing the relationships investigated is as follows:

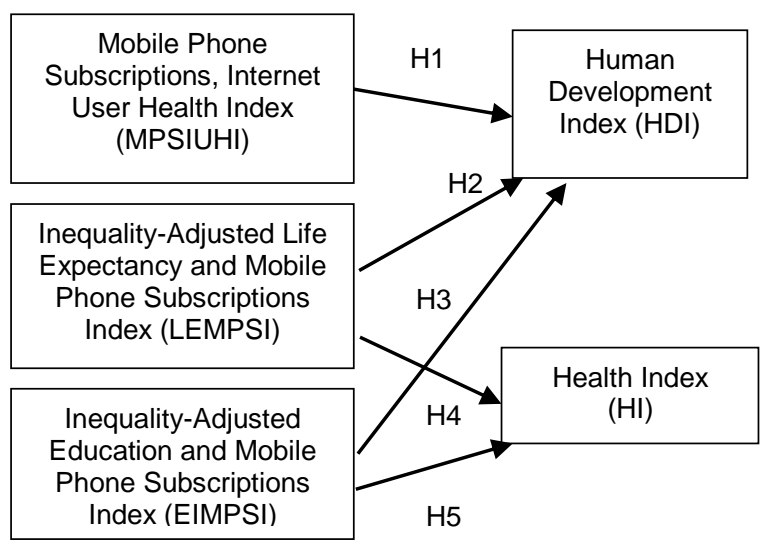

\section{Figure 1: Research Model of mHealth Equity}

mHealth Index: In order to assess the effects of mHealth adoption on the HDI, we created an index comprising of Mobile Phone Subscriptions per 100 
population [31], Internet Usage per 100 population [31] and the Health Index [29]. This index we abbreviate as MPSIUHI, which measures mHealth in this study. Our first hypothesis reflects this relationship:

H1: Mobile Phone Subscriptions Internet Usage Health Index (MPSIUHI) has a positive effect on the Human Development Index.

Inequality Adjusted Life Expectancy Mobile Phone Index: An indicator of social inequalities affecting the ability of people to lead better lives is the "life expectancy index adjusted for inequality in distribution of expected length of life based on data from life tables listed in Main data sources. To ensure that we are assessing the mobile effect, we add the variable Mobile Phone Subscriptions per 100 population [31] to create the Inequality-adjusted Life Expectancy and Mobile Phone Subscriptions Index (LEMPSI). This is the basis of our second hypothesis as follows:

\section{H2: Inequality-adjusted Life Expectancy and Mobile Phone Subscriptions Index (LEMPSI) has a positive effect on the Human Development Index.}

Inequality-adjusted Education and Mobile Phone Index: This indicator of social inequalities also affects the ability of people to lead better lives is the education index adjusted for inequality in distribution of years of schooling based on data from household surveys [29]. To ensure that we are assessing the mobile effect, we add the variable Mobile Phone Subscriptions per 100 population [31] to create the Inequality-adjusted Education and Mobile Phone Subscriptions Index (EIMPSI). This is the basis of our third hypothesis as follows:

H3: Inequality-adjusted Education Index Mobile Phone Subscriptions Index (EIMPSI) has a positive effect on the Human Development Index.

The second outcome of health equity is the Health Index (HI) which measures the life expectancy at birth having a minimum value of 20 and maximum 85 years. To ensure that we measure the effects of social inequalities related to mobile phone usage on health and wellbeing of people, we also assess these indexes in terms of the Health Index. The following hypotheses reflect this part of our research model:

H4: Inequality-adjusted Life Expectancy and Mobile Phone Subscriptions Index (LEMPSI) has a positive effect on the Health Index.
H5: Inequality-adjusted Education Index Mobile Phone Subscriptions Index (EIMPSI) has a positive effect on on the Health Index.

The above hypotheses help us understand the effects of social inequalities measured in terms of life expectancy and education as they relate to mobile phone use on health. In the following section, methods for the data collection and analysis are described.

\section{Methodology}

In order to test the five hypotheses in the above model, data used for this analysis is collected from the United Nations Development Program, World Health Organization and World Bank. The data for the core variables is as follows:

Human Development Index (HDI) is used. The HDI "is a summary measure of average achievement in key dimensions of human development: a long and healthy life, being knowledgeable and have a decent standard of living. The HDI is the geometric mean of normalized indices for each of the three dimensions" [29].

Inequality-adjusted life expectancy index: This is calculated as the HDI life expectancy index value adjusted for inequality in distribution of expected length of life based on data from life tables [29].

Inequality-adjusted education index: The HDI education index adjusted for inequality in distribution of years of schooling based on data from household surveys [29].

Health Index (HI): the life expectancy at birth having a minimum value of 20 and maximum 85 years. HI covered a longer time span [32]. This is part of mHealth index (MPSIUHI)

Mobile Phone Subscriptions (MPS): the country ranking for this variable based on subscriptions per 100 people. Mobile cellular telephone subscriptions are subscriptions to a public mobile telephone service that provide access to the public switched telephone network (PSTN) using cellular technology. The indicator includes (and is split into) the number of postpaid subscriptions, and the number of active prepaid accounts (i.e. that have been used during the last three months). The indicator applies to all mobile cellular subscriptions that offer voice communications. It excludes subscriptions via data cards or USB modems, subscriptions to public mobile data services, private trunked mobile radio, telepoint, radio paging and telemetry services [33]. This is part of mHealth index (MPSIUHI)

Internet Users (IU) is individuals using the Internet as a percentage of the population. Internet users are individuals who have used the Internet from 
any location in the last 3 months. The Internet can be used via a computer, mobile phone, personal digital assistant, games machine, digital TV. This is part of mHealth index (MPSIUHI) [31]

Multiple regression was carried out of a sample of 154 countries for which data was complete for all the variables described above. The results of this analysis is described in the following sections.

\section{Results and Analysis}

Through multiple regression analysis, we found that our research model holds. All five hypotheses are found to be significant. The results of the regression are illustrated in the following figure 2 :

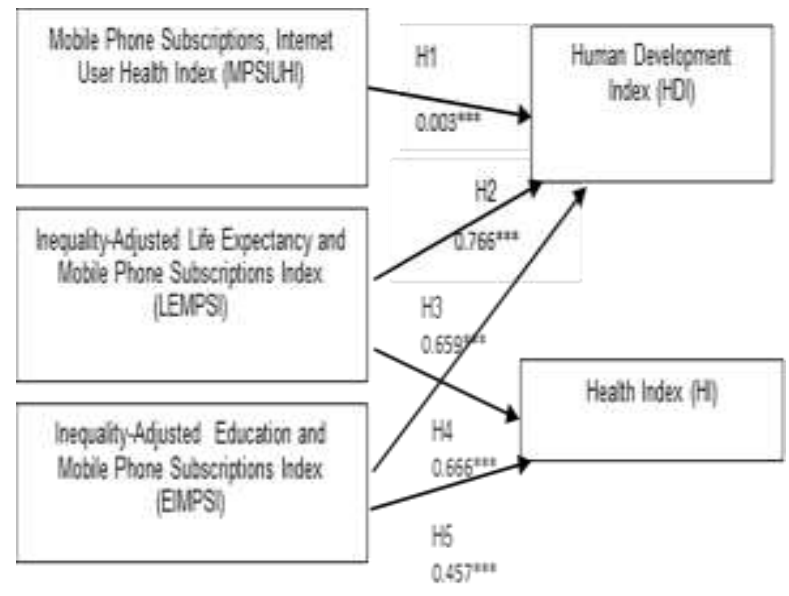

Figure 2: Model of mHealth Equity

As shown in the above model, there is a very strong positive correlation between the mHealth index (MPSIUHI), Inequality-adjusted life expectancy mobile phone index (LEMPSI), Inequality-adjusted education mobile phone index (EIMPSI), and the Human Development Index (HDI). When we tested the model for the dependent variable, Human Development Index, we found that it explains $95.6 \%$ of the variance. We also found that the model is significant for each of the independent variable as follows:

$\mathrm{HDI}=0.362 *(\mathrm{LEMPSI})+0.342 *($ EIMPSI $)+0.001 *(\mathrm{MPS}$ IUHI) +0.226

Table 1: ANOVA Table for Model 1

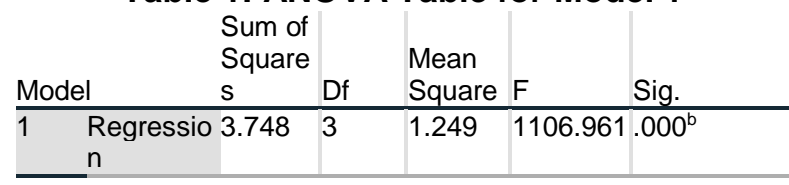

\begin{tabular}{lll|l|l|l}
\hline Residual & .169 & 150 & .001 & \\
\hline Total & 3.917 & 153 & & \\
\hline
\end{tabular}

a. Dependent Variable: Human Development Index (HDI) b. Predictors: (Constant), MPSIUHI, Inequality-adjusted education index, Inequality-adjusted life expectancy index

Based on the first research model, for each unit increase of Inequality-adjusted life expectancy mobile phone index (LEMPSI), HDI will increase by 0.362 unit, while other two independent variables keep constant. For each unit increase of the Inequalityadjusted education mobile phone index (EIMPSI), HDI will increase by 0.342 unit, while other two independent variables keep constant. For each unit increase of the mHealth index (MPSIUHI), The Human Development index (HDI) will increase by 0.001 unit. Overall, there is a positive relationship between the three independent variables with the dependent variable HDI. This is illustrated in the following table 2 .

\section{Table 2: Coefficients for Model 1}

\begin{tabular}{|c|c|c|c|c|}
\hline \multicolumn{2}{|c|}{ Model } & $\begin{array}{l}\text { Std. } \\
\text { Error }\end{array}$ & Beta & Sig. \\
\hline \multirow[t]{4}{*}{1} & (Constant) & .010 & & .000 \\
\hline & $\begin{array}{l}\text { Inequality-adjusted life } \\
\text { expectancy index LEMPSI }\end{array}$ & e. 030 & .443 & .000 \\
\hline & $\begin{array}{l}\text { Inequality-adjusted education } \\
\text { index EIMPSI }\end{array}$ & n.022 & .484 & .000 \\
\hline & mHealth MPSIUHI & .000 & .112 & .000 \\
\hline
\end{tabular}

The above results show that the model holds. The relationship between each of the variables is discussed in the following sub-sections.

\section{1. mHealth and Human Development}

We continue the analysis to understand the potential relationship between mHealth and Human Development. In this sub-section, Hypothesis 1: Mobile Phone Subscriptions Internet Usage Health Index (MPSIUHI) has a positive effect on the Human Development Index is tested. From the results of this analysis, the following model is developed:

\section{$\mathrm{HDI}=0.003 * \mathrm{MPSIUHI}+0.421$}

Table 3: ANOVA Table for Model 2

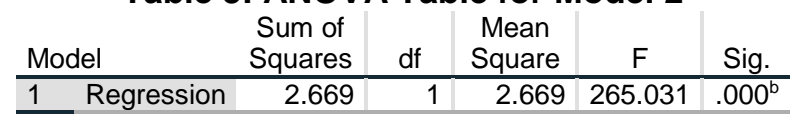




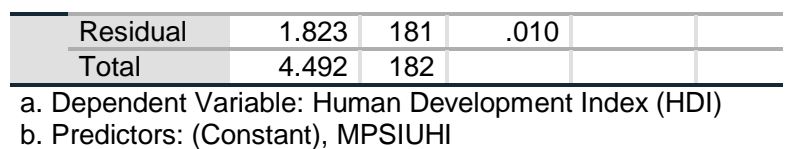

R Square for this test is 0.594 , which means the model explains $59.4 \%$ of the variance from the sample. The model suggests that for each unit increase in mHealth (MPSIUHI), HDI will increase by 0.003 unit. This indicates there is a positive relationship between mHealth and Human Development. These results are illustrated in the following table 4.

Table 4: Coefficients for Model 2 Coefficients $^{\mathrm{a}}$

\begin{tabular}{cc|c|c|c|c|} 
& \multicolumn{2}{c}{$\begin{array}{c}\text { Unstandardized } \\
\text { Coefficients } \\
\text { Model }\end{array}$} & $\begin{array}{c}\text { Standardized } \\
\text { Coefficients }\end{array}$ & & \\
B & Error & Beta & t & Sig. \\
\hline (Constant) & .421 & .019 & & 22.727 & .000 \\
\hline MPSIUHI & .003 & .000 & .771 & 16.280 & .000 \\
\hline
\end{tabular}

a. Dependent Variable: Human Development Index (HDI)

This analysis has shown that mHealth has a positive relationship to human development. This means that improvements in people's lives are taking place as they use mHealth applications.

\subsection{Inequality-adjusted life expectancy mobile use and Human Development}

In the next step, we investigate the relationship between LEMPSI and HDI. In this sub-section, Hypothesis 2: Inequality-adjusted Life Expectancy Mobile Phone Subscriptions Index (LEMPSI) has a positive effect on the Human Development Index is tested. From the results of this analysis, the following model is developed:

HDI $=0.766 *$ LEMPSI +0.184

\begin{tabular}{|c|c|c|c|c|c|}
\hline Model & $\begin{array}{l}\text { Sum of } \\
\text { Squares }\end{array}$ & $\mathrm{df}$ & $\begin{array}{l}\text { Mean } \\
\text { Square }\end{array}$ & $\mathrm{F}$ & Sig. \\
\hline Regression & 3.859 & 1 & 3.859 & 1256.772 & $.000^{\mathrm{b}}$ \\
\hline Residual & .556 & 181 & .003 & & \\
\hline Total & 4.415 & 182 & & & \\
\hline
\end{tabular}

$\mathrm{R}$ Square for this test is 0.874 , which means the model explains $87.4 \%$ of the variance from the sample. The model suggests that for each unit increase of Inequality-adjusted Life Expectancy Mobile Phone Subscriptions Index (LEMPSI), HDI will increase by 0.766 units. This indicates there is a positive relationship between Inequality-adjusted life expectancy mobile use (LEMPSI) and Human Development. These results are illustrated in the following table 6 .

\section{Table 6: Coefficients for Model 3}

\begin{tabular}{lc|c|c|c|c} 
& \multicolumn{2}{c}{$\begin{array}{c}\text { Unstandardized } \\
\text { Coefficients } \\
\text { Std. }\end{array}$} & $\begin{array}{c}\text { Standardized } \\
\text { Coefficients }\end{array}$ & & \\
Model & $\mathrm{B}$ & $\begin{array}{c}\text { Std. } \\
\text { Error }\end{array}$ & Beta & $\mathrm{t}$ & Sig. \\
\hline (Constant) & .184 & .015 & & 12.282 & .000 \\
\hline LEMPSI & .766 & .022 & .935 & 35.451 & .000 \\
\hline
\end{tabular}

a. Dependent Variable: Human Development Index (HDI)

This analysis has shown that Inequality-adjusted life expectancy mobile use has a positive relationship to human development. This means that improvements in people whose expected length of life and use of mobile phones brings about improvements in their lives.

\subsection{Inequality-adjusted education mobile use and Human Development}

In the next step, we investigate the relationship between Inequality-adjusted education mobile use (EIMPSI) and Human Development (HDI). In this subsection, hypothesis 3: Inequality-adjusted Education Index Mobile Phone Subscriptions Index (EIMPSI) has a positive effect on the Human Development Index is tested. From the results of this analysis, the following model is developed:

$\mathrm{HDI}=0.659 *$ EIMPSI+0.339

Table 7: ANOVA Table for Model 4

\begin{tabular}{|c|c|c|c|c|c|c|}
\hline \multicolumn{2}{|c|}{ Model } & $\begin{array}{l}\text { Sum of } \\
\text { Squares }\end{array}$ & df & $\begin{array}{l}\text { Mean } \\
\text { Square }\end{array}$ & $\mathrm{F}$ & Sig. \\
\hline \multirow[t]{3}{*}{1} & Regression & 3.431 & 1 & 3.431 & 1065.198 & $.000^{\mathrm{b}}$ \\
\hline & Residual & .502 & 156 & .003 & & \\
\hline & Total & 3.934 & 157 & & & \\
\hline
\end{tabular}

The R Square for this test is 0.872 , which means the model explains $87.2 \%$ of the variance from the sample. The model suggests that for each unit increase of EIMPSI, HDI will increase by 0.659 unit. This indicates there is a positive relationship between Inequality-adjusted education mobile use and Human Development. These results are illustrated in the following table 8 .

Table 8: Coefficients for Model 4 Unstandardized Standardized

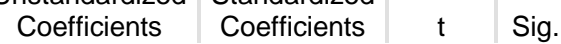




\begin{tabular}{|c|c|c|c|c|c|}
\hline & $\mathrm{B}$ & $\begin{array}{l}\text { Std. } \\
\text { Error }\end{array}$ & Beta & & \\
\hline (Constant) & .339 & .012 & & 29.323 & .000 \\
\hline EIMPSI & .659 & .020 & .934 & 32.637 & .000 \\
\hline
\end{tabular}

a. Dependent Variable: Human Development Index (HDI)

The above analysis suggests that people with more years of schooling adjusted for inequalities use mobile phones, their ability to achieve improvements in their lives increases.

\subsection{Inequality-adjusted life expectancy mobile use and Health Wellbeing}

We continue the analysis by changing the dependent variables to Health Index (HI). Hypothesis 4: Inequality-adjusted Life Expectancy and Mobile Phone Subscriptions Index (LEMPSI) has a positive effect on the Health Index is tested. In this sub-section, the relationship between Inequality-adjusted life expectancy mobile use (LEMPSI) and Health (HI) is investigated. From the results of this analysis, the following model is developed:

\section{$\mathrm{HI}=0.666 *$ LEMPSI +0.343}

\begin{tabular}{|c|c|c|c|c|c|c|}
\hline \multicolumn{2}{|c|}{ Model } & $\begin{array}{l}\text { Sum of } \\
\text { Squares }\end{array}$ & df & $\begin{array}{l}\text { Mean } \\
\text { Square }\end{array}$ & $\mathrm{F}$ & Sig. \\
\hline \multirow[t]{3}{*}{1} & Regression & 2.966 & 1 & 2.966 & 6826.637 & $.000^{\mathrm{b}}$ \\
\hline & Residual & .080 & 183 & .000 & & \\
\hline & Total & 3.046 & 184 & & & \\
\hline
\end{tabular}

The R Square for this test is 0.974 , which means the model explains $97.4 \%$ of the variance from the sample. The model suggests that for each unit increase of LEMPSI, HI will increase by 0.666 unit. This indicates there is a positive relationship between Inequalityadjusted life expectancy mobile use and Human Development. These results are illustrated in the following table 10.

\begin{tabular}{|c|c|c|c|c|c|}
\hline & \multicolumn{2}{|c|}{$\begin{array}{l}\text { Unstandardized } \\
\text { Coefficients }\end{array}$} & \multirow{2}{*}{$\begin{array}{c}\text { Standardized } \\
\text { Coefficients } \\
\text { Beta }\end{array}$} & \multirow[b]{2}{*}{$t$} & \multirow[b]{2}{*}{ Sig. } \\
\hline & B & $\begin{array}{l}\text { Std. } \\
\text { Error }\end{array}$ & & & \\
\hline & .343 & .006 & & 61.519 & .000 \\
\hline & .666 & .008 & .987 & 82.623 & .000 \\
\hline
\end{tabular}

a. Dependent Variable: Health Index (HI)

These results suggest that Inequality-adjusted life expectancy mobile use has a positive relationship to health. This means that people whose expected length of life through use of mobile phones helps them to be healthier. Improvements in health and wellbeing can be found through the use of mobile phones with disparities are addressed.

\subsection{Inequality-adjusted education mobile use and Health Wellbeing}

Finally we investigate the relationship between Inequality-adjusted education mobile use and Health Wellbeing. In this sub-section, Hypothesis 5: Inequality-adjusted Education Index Mobile Phone Subscriptions Index (EIMPSI) has a positive effect on the Health Index is tested. From the results of this analysis, the following model is developed:

\section{$\mathrm{HI}=0.457 *$ EIMPSI +0.54}

Table 11: ANOVA Table for Model 6

\begin{tabular}{|c|c|c|c|c|c|c|}
\hline \multicolumn{2}{|c|}{ Model } & $\begin{array}{l}\text { Sum of } \\
\text { Squares }\end{array}$ & df & $\begin{array}{c}\text { Mean } \\
\text { Square }\end{array}$ & $\mathrm{F}$ & Sig. \\
\hline \multirow[t]{3}{*}{1} & Regression & 1.646 & 1 & 1.646 & 241.404 & $.000^{\mathrm{b}}$ \\
\hline & Residual & 1.064 & 156 & .007 & & \\
\hline & Total & 2.710 & 157 & & & \\
\hline
\end{tabular}

The R Square for this test is 0.607 , which means the model explains $60.7 \%$ of the variance from the sample. The model suggests that for each unit increase of EIMPSI, HI will increase by 0.457 unit. This indicates there is a positive relationship between Inequalityadjusted education mobile use and Health Wellbeing. These results are illustrated in the following table 12 .

\section{Table 12: Coefficients for Model 6}

\begin{tabular}{lc|c|c|c|c} 
& \multicolumn{2}{c}{$\begin{array}{c}\text { Unstandardized } \\
\text { Coefficients } \\
\text { Model }\end{array}$} & $\begin{array}{c}\text { Standardized } \\
\text { Coefficients }\end{array}$ & & \\
Std. & B & Error & Beta & $\mathrm{t}$ & Sig. \\
\hline (Constant) & .540 & .017 & & 32.108 & .000 \\
\hline EIMPSI & .457 & .029 & .779 & 15.537 & .000 \\
\hline a. Dependent Variable: Health Index (HI)
\end{tabular}

The above analysis suggests that when people with more years of schooling adjusted for inequalities use mobile phones, their health and wellbeing improves.

The results of the above analysis are all very positive. While one would normally not expect to find all the results to be so highly significant, in the case of our analysis suggests that the ability to stay healthy is very much related to the use of mobile phones. education and life expectancy are also strongly related to the use of mobile phones. The reason for such strong correlations point to ways in which mHealth 
applications and used to achieve health equity and are discussed in the following section.

\section{6. mHealth Implications for Health equity}

Equitable access to healthcare involves addressing the disparate needs of people while not necessarily offering universal public access to healthcare. The above analysis suggests that equitable access to healthcare can be offered through mHealth implementations. The above analysis also suggests that the social determinants of in equalities of life expectancy and education through the use mobile phones can enable people to bring about improvements in their lives and be healthy. The implications of these findings for achieving health equity through mHealth implementation are as follows:

Combatting spread of infectious diseases: In order to achieve equitable access to healthcare, the spread of diseases can be curtailed through the use of mobile communication infrastructures by public health authorities. As human travel is one of the key factors affecting the spread of disease in Africa, a group of researchers, including Caroline Buckee, an epidemiologist at the Harvard School of Public Health, have mapped precisely how human travel affects the spread of malaria in Kenya by using cell-phone location data. By capturing the anonymized travel habits of nearly 15 million Kenyans by gleaning their movements from 11,920 cell towers, and then mapping the data against the incidence of malaria as recorded by health officials, future outbreaks can be contained [34].

Remote monitoring. Location based mHealth applications can further assist the independent living of persons with disabilities and/or multiple chronic conditions and in epidemiology/public health surveillance, community data collection and remote monitoring of patients [27]. The increased popularity of smartphones has led more patients to proactively manage their care while on the go using specific mobile applications containing functionalities such as GPS tracker for Alzheimer's patients, not available on desktop computers. In particular, the rise of open source software development communities has meant that mobile applications for healthcare have enabled access to basic healthcare easier.

Disease diagnosis, drug reference, and medical calculator applications were reported as most useful by healthcare professionals and medical or nursing students. An example of such as system is FrontlineSMS which allows citizens in remote areas to communicate their specific problems and needs directly to health workers who would not otherwise have the capacity to interact with the remote populations. Their reliability for making clinical decisions, protection of patient data with respect to privacy; impact on the doctor-patient relationship; and proper integration into the workplace remains limited [36].

Disaster Response systems for community based health reporting are becoming more readily available for free through open source platforms. An example is Ushahidi which gained broad recognition and acclaim as an important resource for citizens and responders in the aftermath of the earthquake in Port-au-Prince, Haiti. This system provides an open-source platform for collecting individual reports from users through SMS, Web, and email and provides tools for translating, classifying, and georeferencing these reports; the newest version of the platform further allows for submission via voice message - essential for illiterate users. Aggregated information is presented on a map-based interface accessible via Web and mobile phone. Another is notable example is GeoChat, also a suite of open-source software tools aims to achieve faster and more coordinated responses to disease outbreaks and natural disasters. GeoChat enables team members to communicate their position and important information using text messages, email, or a Web browser, with data instantly synchronized on every user's mobile [37].

These categories of mHealth applications are just beginning to offer equitable health options. The challenge remains as to how they may be implemented to suit the local conditions in which their users live. While public private partnerships may be suitable for some regions, other areas may require more targeted support for epidemics or community healthcare needs.

\section{Conclusions, Contributions, and Future Research}

This paper has uncovered the role of mHealth and social inequalities on the ability of people to lead better lives and be healthy. It investigates the role of social inequalities, education and life expectancy, on human development and heath. A model is investigated with independent variables that are three indexes created for this study: mHealth (Mobile Phone Subscriptions, Internet User Health Index), two indexes that help us measure social inequalities (Inequality-Adjusted Life Expectancy and Mobile Phone Subscriptions Index (LEMPSI) and Inequality-Adjusted Education and Mobile Phone Subscriptions Index (EIMPSI)). The dependent variables in our model are the Human Development Index (HDI) and Health Index (HI). The dependent variables help us understand the extent to which people can live the lives they chose to live 
(HDI) and be healthy (HI). All five of the hypotheses in this model were found to be significant.

These findings have important implications for mHealth support for health equity. mHealth applications can support health equity by combatting spread of infectious diseases, remote monitoring of patients, disease diagnosis, and disaster response. While these categories may not be exhaustive, they explain the significant relationships between the mHealth and social inequality mobile use indexes and their effect on human development and heath.

The contribution of this research is in understanding the role of social inequalities in and mHealth in enabling people to bring about improvements in the lives they lead and in their health outcomes. An important limitation of this research is that it does not explicitly consider environmental and other social determinants that could potentially have an even more significant effect on health equity. Future research will have to include additional indicators from the World Health Organization's Global Health Equity monitor to create and investigate a more comprehensive model.

\section{References}

[1] A. Sen, "Why health equity?," Health Econ, vol. 11, no. 8, pp. 659-66, Dec 2002.

[2] "Building on values: the future of health care in Canada : final report / Roy J. Romanow, Commissioner. : CP32-85/2002E-IN - Government of Canada Publications - Canada.ca," 2002-07-01 2002.

[3] D. Hartley, "Rural health disparities, population health, and rural culture," American Journal of Public Health, vol. 94, no. 10, pp. 1675-1678, 2004.

[4] B. Starfield, L. Shi, and J. Macinko, "Contribution of primary care to health systems and health," The milbank quarterly, vol. 83, no. 3, pp. 457-502, 2005.

[5] J. Wakerman and J. S. Humphreys, "Sustainable primary health care services in rural and remote areas: Innovation and evidence," Australian Journal of Rural Health, vol. 19, no. 3, pp. 118124, 2011.

[6] D. S. Kringos, W. G. Boerma, A. Hutchinson, J. Van der Zee, and P. P. Groenewegen, "The breadth of primary care: a systematic literature review of its core dimensions," BMC health services research, vol. 10 , no. 1 , p. $65,2010$.

[7] M. N. K. Boulos, A. C. Brewer, C. Karimkhani, D. B. Buller, and R. P. Dellavalle, "Mobile medical and health apps: state of the art, concerns, regulatory control and certification," Online journal of public health informatics, vol. 5, no. 3, p. 229, 2014.
[8] P. J. Silvia, Exploring the psychology of interest. oxford university Press, 2006.

[9] mHealthIntelligence. (2017). mHealth Data Adds Detail, Meaning to Population Health Programs. Available:

https://mhealthintelligence.com/news/mhealthdata-adds-detail-meaning-to-population-healthprograms

[10] (2018). Measuring the Information Society Report 2017. Available: https://www.itu.int/en/ITUD/Statistics/Pages/publications/mis2017.aspx

[11] M. Kay, J. Santos, and M. Takane, "mHealth: New horizons for health through mobile technologies," World Health Organization, vol. 64, no. 7, pp. 6671, 2011.

[12] S. Qureshi, C. Noteboom, and A. M. Schumaker, "Mobile access for patient centered care: The challenges of activating knowledge through health information technology," in System Sciences (HICSS), 2015 48th Hawaii International Conference on, 2015, pp. 3227-3236: IEEE.

[13] P. Braveman and S. Gruskin, "Defining equity in health," Journal of Epidemiology \& Community Health, vol. 57, no. 4, pp. 254-258, 2003.

[14] X. Liu et al., "Can rural health insurance improve equity in health care utilization? A comparison between China and Vietnam," Int J Equity Health, vol. 11, p. 10, Feb 292012.

[15] F. M. Knaul et al., "The quest for universal health coverage: achieving social protection for all in Mexico," The Lancet, vol. 380, no. 9849, pp. 12591279, 2012.

[16] P. Braveman, "Health disparities and health equity: concepts and measurement," Annu Rev Public Health, vol. 27, pp. 167-94, 2006.

[17] J. Costa-Font and C. Hernández-Quevedo, "Measuring inequalities in health: What do we know? What do we need to know?," Health Policy, vol. 106, no. 2, pp. 195-206, 2012.

[18] A. Case, A. Fertig, and C. Paxson, "The lasting impact of childhood health and circumstance," Journal of health economics, vol. 24, no. 2, pp. 365-389, 2005.

[19] (2017). WHO | About social determinants of health. Available: http://www.who.int/social_determinants/sdh_defini tion/en/

[20] R. J. Laumbach and H. M. Kipen, "Respiratory health effects of air pollution: update on biomass smoke and traffic pollution," Journal of allergy and clinical immunology, vol. 129, no. 1, pp. 3-11, 2012.

[21] H. Mustafić et al., "Main air pollutants and myocardial infarction: a systematic review and meta-analysis," Jama, vol. 307, no. 7, pp. 713-721, 2012.

[22] L. Tzivian, "Outdoor air pollution and asthma in children," Journal of Asthma, vol. 48, no. 5, pp. 470-481, 2011.

[23] J. Corburn, "Urban place and health equity: Critical issues and practices," International journal of 
environmental research and public health, vol. 14 no. 2, p. 117, 2017.

[24] J. G. Kahn, J. S. Yang, and J. S. Kahn, "'Mobile' health needs and opportunities in developing countries," Health Aff (Millwood), vol. 29, no. 2, pp. 252-8, Feb 2010.

[25] B. Cliff, "Patient-centered care: The role of healthcare leadership," Journal of Healthcare Management, vol. 57, no. 6, pp. 381-383, 2012.

[26] S. E. Gabriel and S.-L. T. Normand, "Getting the methods right - the foundation of patient-centered outcomes research," New England Journal of Medicine, vol. 367, no. 9, pp. 787-790, 2012.

[27] M. N. Boulos, S. Wheeler, C. Tavares, and R. Jones, "How smartphones are changing the face of mobile and participatory healthcare: an overview, with example from eCAALYX," Biomed Eng Online, vol. 10, p. 24, Apr 52011.

[28] K. F. B. Payne, H. Wharrad, and K. Watts, "Smartphone and medical related App use among medical students and junior doctors in the United Kingdom (UK): a regional survey," BMC medical informatics and decision making, vol. 12, no. 1, p. $121,2012$.

[29] (2018). Human Development Index (HDI) | Human Development Reports. Available: http://hdr.undp.org/en/content/humandevelopment-index-hdi

[30] P. A. Braveman et al., "Health disparities and health equity: the issue is justice," American journal of public health, vol. 101, no. S1, pp. S149S155, 2011

[31] (2018). Individuals using the Internet (\% of population) | Data. Available: https://data.worldbank.org/indicator/IT.NET.USER .ZS
[32] (2016, June 14, 2018). WHO | Mobile health (mHealth) for tobacco control. Available: http://www.who.int/tobacco/mhealth/en/

[33] (2018, June 14, 2018). Mobile cellular subscriptions (per 100 people) | Data. Available: https://data.worldbank.org/indicator/IT.CEL.SETS. $\mathrm{P} 2$

[34] D. Talbot, "Kenya's Startup Boom," Technology Review. MIT, Cambridge, MA. http://www. technologyreview. com/communications/39673, 2012.

[32] CSDH (2008). Closing the gap in a generation: health equity through action on the social determinants of health. Final Report of the Commission on Social Determinants of Health Geneva, World Health Organization.

[33] Ottersen OP . The political origins of health inequity: prospects for change. The LancetUniversity of Oslo Commission on Global Governance for Health. The Lancet 2014;383:63067

[35] RIVM. Towards a healthier Netherlands. Key findings of the Dutch Public Health Status and Foresight study (PHSF). Bilthoven: National Institute for Public Health and the Environment (RIVM); 2014

[36] Qureshi, Sajda, and Jason Xiong. "The Role of Mobile Phones in the Provision of Equitable Health Care for Human Development." (2017).

[37] Freifeld, C. C., Chunara, R., Mekaru, S. R., Chan, E. H., Kass-Hout, T., Iacucci, A. A., \& Brownstein, J. S. (2010). Participatory epidemiology: Use of mobile phones for community-based health reporting. PLoS Medicine, 7(12), 1-5. https://doi.org/10.1371/journal.pmed.1000376 